\title{
Examining Student Standpoint: Blended Learning as a Beneficial Teaching Approach
}

\begin{tabular}{l} 
ARTICLE INFO \\
\hline \hline Article history: \\
Received: April 3, 2019 \\
Revised: July 2, 2019 \\
Accepted: September 10, 2019 \\
\hline Keywords: \\
Blended Learning, \\
Teaching approach, \\
Blended learning benefits, \\
Malaysian universities, \\
E-learning
\end{tabular}

Clonflict of Interest:

None

Funding:

None

Prashalini Naidu ${ }^{1} \&$ Farah Idayu Razali ${ }^{2}$

${ }^{1 \& 2}$ Universiti Tenaga Nasional, Malaysia

\begin{abstract}
The purpose of this paper is to shed light on the benefits of blended learning as a method and its contribution to teaching. It was discovered that blended learning isn't just an ordinary teaching method, but its usage reduces cost. Current Malaysian working environment and its employers demand certain skills and therefore Malaysian graduates are encouraged to be IT savvy and technology wise. Blended learning will help equip students with e-learning knowledge, but it doesn't take away their face to face interactions with their lecturers in class. Blended learning combines both the virtual and real class experience for students. This paper seeks to discover the benefits of blended learning from a student viewpoint by using focus groups. The outcome suggest that the student's view blended learning as an effective approach for cost efficiency, to manage their study time, accessibility, promotes efficiency and also encourages e-learning.
\end{abstract}

Corresponding Author: Prashalini Naidu, Universiti Tenaga Nasional: prashalini@uniten.edu.my (C) Prashalini Naidu \& Farah Idayu Razali

This is an open access article under the CC BY-SA 4.0 international license.

\section{Introduction}

What is the ideal teaching method used in universities by academicians? Truth to be told, every lecturer has their very own preference of effective teaching method. The existence of a wide variety of teaching options; from traditional chalk and board, role playing, brainstorming, discussion and currently e learning; educators and students are both spoiled for choice. The introduction of blended learning in the early 1999 is an addition to this and opened up the option for a mix method. Smythe (2011) states that even though it first appeared in the literature around 1999 it is rather difficult to find a widely accepted meaning of blended learning despite the exposure of the term in higher education. Irrespective of any concerns over its definition, the use of the concept of blended learning has become thoroughly accepted and is ubiquitous in all forms of education and training. Its adoption and acceptance may well be due to the fact that Malaysia encourages education and would certainly embrace different delivery methods of education. In spite of having its challenges, Malaysia still strives to provide the basic need of education to its people. Naidu and Derani (2016) explains that one of the poignant objectives of the Malaysian government is to help Malaysia emerge in a way that it reaches year 2020 successfully. This goal has led the way for various exchanges in terms of culture, transfer of knowledge, export/import of goods internationally, and evens the transfer of people across borders. With that in mind, a rather significant cause it has endowed upon us is the opportunity to receive education. However, despite receiving access to education, our young graduates lack many skills, and many are unable to perform when they begin in the workforce.

The demand for a well-educated workforce has driven many countries to reconsider and review their education systems. An education system has to be suited to the demands of the technological age so that a competitive edge can be sustained (Agboola, 2006). With regards to this, one significant question that arises is whether the right approach or method is being used in the classrooms to convey lectures. Damodharan and Rengarajan 
(2007) have found that most teachers and students in universities felt that the traditional lecture approach in classroom is of limited effectiveness in both teaching and learning. It is then apt to suggest that with the latest era of technology, students and lecturers may prefer other teaching methods compared to the old chalk and board lecture methods. Many of the changes in the manner students learn at university are well known although the nature and extent of their impact is not. Digital revolution changes mechanical to digital technologies and establishes new requirements for instruction, assessment and learning mechanisms and processes, which can be defined under the umbrella of education 3.0 on challenges coming from the expected new industrial revolution (Railean, 2017). In spite of knowing the existence of other forms of teaching method such as elearning and blended learning, yet some lecturers and students are afraid to leave their comfort zone. Nonetheless, Malaysia is moving towards its Vision 2020 and the adoption of such methods like e-learning and blended learning in classrooms cannot be kept away.

\section{Literature Review}

In recent years "blended learning" has gained acceptance as it combines traditional face to- face teaching in varying mixes with other elements, notably on-line supported activity (Fleck, 2012). Blended learning puts together the vibrant nature of the classroom with the self-paced environment available in an online setting (Clark cited in Cavage, 2012). Blended learning brings a new meaning to learning as it is refreshing. Blended learning is an innovative teaching method that presents students with a flexible teaching climate (Adas \& Bakir, 2013).

Rosset, Douglis and Frazee in Azizan (2010) states that blended learning is perceived as an integrated strategy for delivering on promises about learning and performance where it involves planned combination practices such as coaching by a supervisor; participation in an online class; breakfast with colleagues; competency descriptions; reading on the beach; reference to a manual; collegial relationships and participation in seminars, workshops and online communities. Yuen (2010) mentions that forms of blended learning are extremely effective because of its ability to facilitate a community of inquiry. At the heart of a community of inquiry there exists three key elements: cognitive presence, social presence and teaching presence. Blended learning primarily combines the positive attributes of both traditional and non-traditional method of learning.

Blended learning is important for various reasons. It is a vital instrument to access the present-day technologies and resources tailor the learning experience for each student. But, the traditional teaching such as face-to-face is still needed for monitoring and supervisory. Sometimes, it is complex to comprehend how digital technologies are actually used in teaching and learning and what are their impacts on higher education, as there are simply too many new developments in digital tools and researchers cannot catch up with all of these (Lai, 2011). However it is undeniable that blended learning is a necessity of rising education quality which allow and facilitates the interaction between lecturer and students in a different manner. For instance, UNITEN uses Moodle which is a designated tool to improve and provide educators, administrators and learners with a single robust, secure and integrated system to create personalized learning environments (Benta, Bologa \& Dzitac, 2014).

Blended learning is special in its own way and adds value to the education environment and its institution. One of the benefits of blended learning is that it reduces cost. According to Singh and Reed (2001) bringing together different delivery modes has the ability to balance out and optimize the learning program development and deployment cost and time. In simple terms, a mix teaching method like blended learning would be easy to manage with reference to time and cash therefore contributing to a reduction in cost for lecturers and teachers. Blended learning can be summed up as a lack of peer contact and social interaction, substantial initial costs and efforts for preparing content materials, system maintenance and a need for appropriate tutorial support (Kinshuk \& Yang, 2003;Wu, Tennyson, \& Hsia, 2008;Wu, Tennyson, Hsia, \& Liao, 2010). Haro (2009) says that blended learning minimizes the need for training or tutorial because they all use the same resource. There are people more outgoing to which costs them nothing to communicate either through network or in person (Duță \& Martínez-Rivera, 2015).

Apart from that, blended learning is used wisely by students as a way to manage their study time. The online component of blended learning provides the students a chance to learn when and where they want. Basically, it offers students the comfort and flexibility to choose the time they study with no controlled classroom timetable (Marsh, 2012). Study management takes precedence for students to develop their own space and time in order to plan their student activities and at the same time focus on their studies. Blended learning provides the transition from centralization of transmittal teaching towards awareness of the added value of a learning process in which students have a more active role in building knowledge. (Monteiro, Leite \& Lima, 2013) The introduction of electronic component of the blended course opens new possibilities for new material presentation in an understandable form (Krasnova, 2015).

One of the benefits of blended learning is also its accessibility. Lecturers have the option to upload their class related materials online and students may have access to these study materials in a quick and easy manner. The adoption of new technology can permit content to be more accessible and flexible to lecturers and students 
(Bath \& Bourke, 2010). This is further emphasized by Singh and Reed (2001) when they mentioned that a classroom activity or session limits access to only those who can participate at a fixed moment of time and location, whereas a virtual classroom activity is inclusive of a remote audience, and when followed up with recorded knowledge objects (ability to playback a recorded live event), can be made available to those who could not attend at a specific time or place. From a student perspective, instructors should consider using a wide variety of technological tools to deliver course materials and to assist with student learning (Hung \& Chou, 2015). In order to adopt knowledge of the contents of the field, it is better and easier access to more content and compression of matter (Duță \& Martínez-Rivera, 2015). Blended learning helps students develop skills in finding the information properly to choose and refine useful information useless to continue the amount of information we process (Duță \& Martínez-Rivera, 2015).

In addition to the benefits mentioned earlier, blended learning is also said to increase efficiency. Students gain better understanding of the subject taught through video presentation. Online lectures are seen as effective activities for both the educators and the students (Wai \& Seng, 2014). Current research at the University of Tennessee and Stanford provides sufficient evidence that a blended learning program actually improves learning outcomes by giving a better match between how a learner wants to learn and the learning program that is offered (Singh \& Reed, 2001). The efficiency of blended learning exist when transition from a traditional learning model to an integrated one where electronic environments and resources are widely used (Krasnova, 2015).

Krasnova (2015) further explains that $t$ generates a positive experience of integrating blended learning, when the study load distributed evenly and didactically justified between face-to-face and online models of learning. Lecturers gain efficiency as the load is shifted from traditional classroom-based education to online education hence many instructors no longer have direct control of the teaching process and they act more as facilitators than as traditional lecturers (Arbaugh, 2010; Schoonenboom, 2012). Duță and Martínez-Rivera (2015) found that, there are $87.7 \%$, improvement in learning when using blended learning as it helps the learning dynamics and classes are more enjoyable.

Lastly, blended learning is also seen as an approach to encourage e-learning among students and the younger generation. These days the trend of e-learning is gaining popularity day by day and one of the tools to implement this concept is through Blended Learning (Kaur, 2013). Educators have made efforts to integrate emerging Internet technologies into the teaching and learning process in higher education (Roby, Ashe, Singh, \& Clark, 2013). Hung and Chou (2015) found that the current study's sample of college students who were engaged in blended learning and college students who were engaged in online learning has exhibited the greatest weight in the dimension of course designer and organizer. The approach of e-learning has been changing up do proposal from learning really motivators and even thrilling (Bach \& Fores, 2007). Furthermore, blended learning supports communication with student's bidirectional, as the teachers and students are in the same space (Haro, 2009).

With so much being said and documented on blended learning, it is critical to note that blended learning application and adoption do face some problems as well. Moskal, Dziuban and Hartman (2013) mentions that dependable and right infrastructure must be in place to support students and faculty. Continuous evaluation can most definitely track the impact of blended learning on students, faculty, and the institution. These data are formulated to inform stakeholders and impact policy to improve faculty development and other support structures necessary for success. Apart from this, other authors have also cautioned the usage of blended learning. Woodall (2010) cited in Douglas, Lang and Colasante, (2014) realizes the complexity of mixing of synchronous and asynchronous learning across the two modes but cautions against a hurried mix of modes and media; blended learning must form a balance between student learning benefits and the intended learning outcomes.

Another issue pertaining to blended learning is the element of e-learning itself. It can be jarring for some and the impact may be confusing for some students. Croft, Dalton and Grant (2010) explains that the famed distance education programmes, taught through web-based media, fails the difficulty in preparing, delivering and studying on such programmes. The preparation and distribution of quality material and fulfilling learning experience are key challenges. The physical and temporal separation of tutor and student, and between students themselves, can initiate feelings of isolation. Students reported confusion, anxiety and frustration due to the perceived lack of prompt or clear feedback from the instructor and from ambiguous instructions on the course website and in e-mail messages from the instructor.

Besides that, instructors themselves may find themselves in a dilemma to teach in a foreign or unfamiliar method such as blended learning. Instructors in asynchronous online environments are also challenged to delivery content in the familiar classroom format of lecture supported by PowerPoint slides and writing or drawing on a blackboard or white board. 


\section{Research Methodology}

A qualitative method was used in this research. Qualitative designs are appropriate for studies that seek to gain insight about a particular issue. This paper sought to establish the benefits of the blended learning teaching method from the university student view point. The qualitative method offers the advantage of allowing researchers to obtain in-depth feedback and clarity from participants in a more proactive, and interactive manner.

Choosing the proper sample size for a research study rests on what is to be found and why and how the findings are to be applied (Patton, 1990). In this study, participants were selected based on some common criteria like their experiences with respect to the research domain. Students are the stakeholders in a higher learning institution and their standpoint and comments on effective teaching is crucial for improvement purposes. Data used in this study were collected from Business students from a single higher learning institution over their Semester 2, 2016/2017. The focus groups took place in January 2017.

A focus group method was adopted for this study. Focus groups are a form of group interview that capitalises on communication between research participants in order to generate data (Kitzinger, 1995). The focus group strategy enables spontaneous and quick information exchange, and expression of the participants' knowledge, and thoughts.

Participants participated in 14 focus groups of 70 students. The aim of conducting the focus group is to explore some of the benefits of blended learning as a useful teaching method. Prior to the session, all participants were already exposed to blended learning scenarios in their previous classes and therefore blended learning activities were not an unfamiliar method for them. Students were informed about the purpose and basic rules of focus group. Researchers asked for volunteers for each to be a leader of a group and gave a question guide to lead their groups. By insisting that volunteers led the groups, the effects of the researchers' bias on the eventual results of the study were reduced. Participants were asked to discuss their responses to the questions. The questions are designed as short, open-ended, and one-dimensional (i.e., what was your experience like? Or can you give me an example?) to generate responses from participants. The questions addressed participants' experience in classrooms and required them to suggest some advantages or positive impacts of blended learning. The participants were then asked specifically what teaching strategies that helped their learning and created a positive climate in class.

\section{Results and Discussion}

All details and particulars gathered from the focus groups were transcribed and content analysed. All focus group sessions were developed to represent the issues of this study. A number of recurring themes emerged from the data such as cost efficiency, study management, accessibility, efficiency, and e-learning. The frequency of each theme was recorded and analyzed. Only the most frequently occurring themes were recorded and placed in Table 1. Table 1 shows five themes from cost efficiency, study management, accessibility, efficiency and e-learning and its number of recurrences

Table 1: Benefits of blended learning for teaching method

\begin{tabular}{|c|c|c|c|}
\hline No & Themes & Benefits of blended learning & $\begin{array}{ll}\text { Frequency } & \text { (No of } \\
\text { Similar } & \text { Benefits } \\
\text { Recurring) } & \end{array}$ \\
\hline 1 & Cost efficiency & $\begin{array}{lrrr}- & \text { Save } & \text { money } & (8) \\
- & & \text { Paperless } \\
- & \text { Cost } & \text { efficiency } & (3) \\
- \text { Low budget }(3) & & \end{array}$ & 15 \\
\hline 2 & Study Management & $\begin{array}{l}\text { - It will reduce time for students by opening the } \\
\text { document from the data } \\
\text { - Save energy and time } \\
\text { - It is very easy and convenient for students to share } \\
\text { information with } \\
\text { - Student is being more discipline (2) }\end{array}$ & 14 \\
\hline 3 & Accessibility & $\begin{array}{l}\text { - Easy to access to get information (7) } \\
\text { - Can refer anytime and anywhere (3) } \\
\text { - Can be easy to store and distribute the information } \\
\text { to students (2) }\end{array}$ & 12 \\
\hline
\end{tabular}




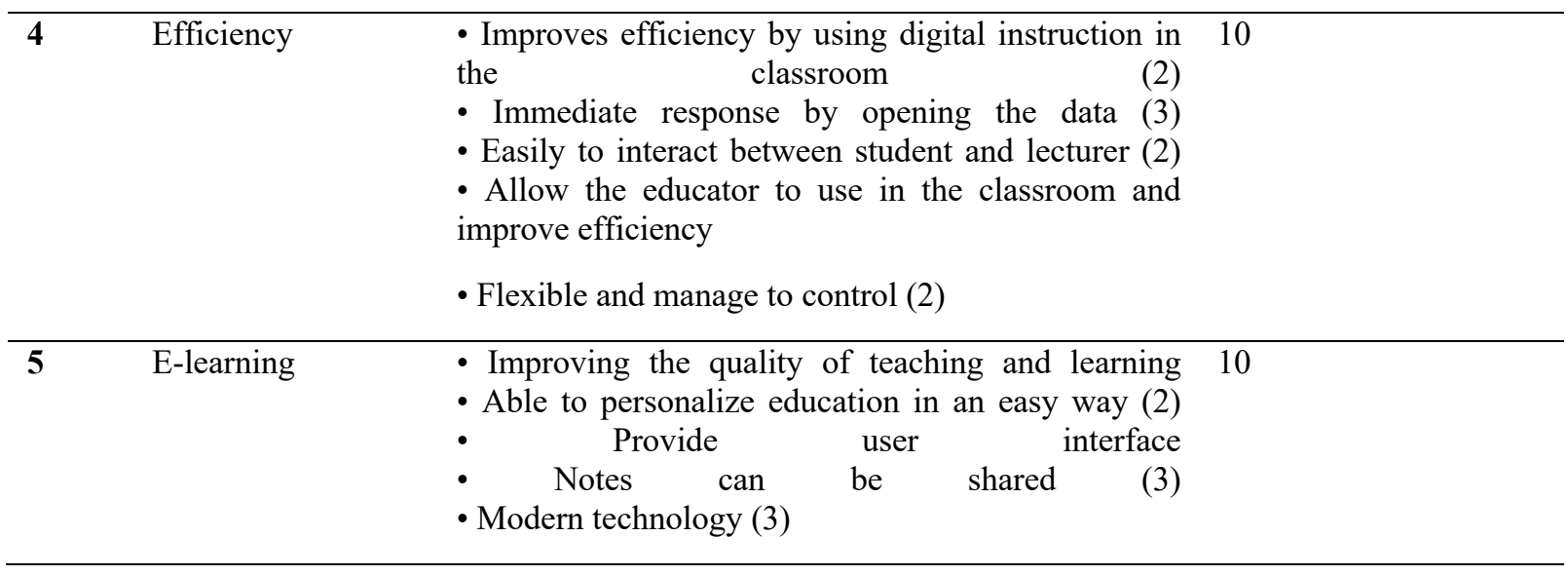

The main findings of this paper highlight the five specific benefits of blended learning method for teaching based on student's perspective. It is discovered that these positive impacts of blended learning in our education that means finally a transformative learning was introduced to the students. As the analysis shows, there has significant blended learning on reducing the cost, helps student study management more efficient and practical and the accessibility through internet also very convenient, helps students supporting integration of blended learning in the process of teaching method. These identified themes are presented in Table 1 and Figure 1. The focus group study revealed that the majority of participants considered that blended learning for teaching method can reduce cost in meeting their goals by using the sound instructional design ideas and principles; built and delivered courseware over the Internet (Moreno-Ger, et al 2010). This is followed by $23 \%$ of the respondents feel that study management provides autonomy, students to be responsible in their learning, which calls for self-discipline and self-motivation (Smyth et. al., 2012). The findings in the current study also support the proposition that the most important role of an online instructor is to act as an instructional designer who plans and prepares the course and who provides direct instruction (Ke, 2010). Hence this gives strong indication that students are responsible to manage their own studying time as their educators provide the right materials and merely facilitates. Duță and Martínez-Rivera (2015) found that $80 \%$ shows that the social networks and online activities as such make students to learn autonomously and independently. Besides that, the respondents also felt accessibility by using an electronic device through internet is also a benefit and hence that generated $20 \%$. Based on Akkoyunlu and Yilmaz-Soylu (2008), students are able to access learning materials on the $\mathrm{Web}$ as and when needed. Furthermore, the recurring theme at $16 \%$ are efficiency and e-learning, where based on Dorin Herlo (2015) it is a positive impact of blended learning in education, the information to transform it into a useful gain and effective for both student and lecturer. Thus, students embrace the possibilities provided by technology to allow them to engage in learning activities at any time and any place (Glogowska et al., 2011; Lancaster et al., 2011).

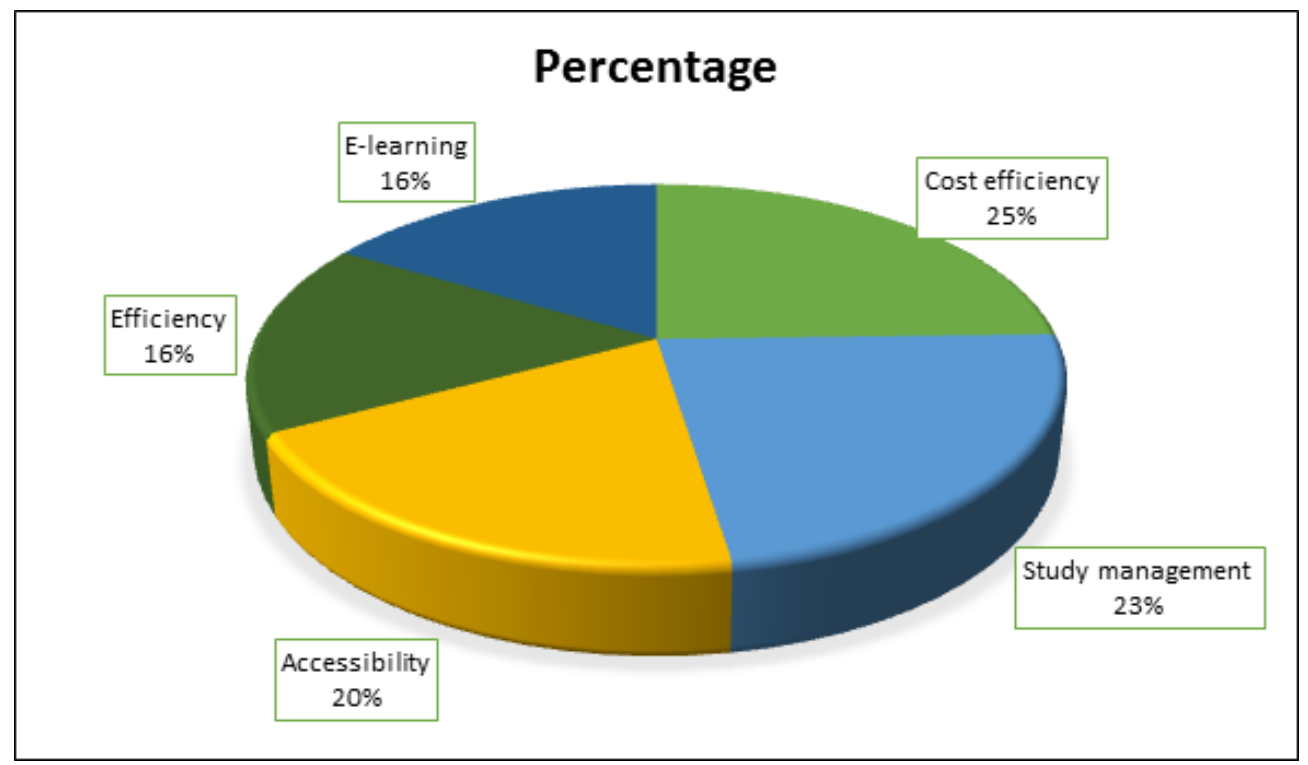

Figure 1: Benefits of blended learning as a teaching method 


\section{Future Research}

Essentially, blended learning has penetrated into many universities and its proliferation has been welcomed. Students may receive the benefit from both sides of these learning methods. Blended learning is an alternate method that lecturers may use to grab the attention of students and actively engage them in the classroom. Some of the limitations of the study include the fact that the focus groups were conducted within a single higher education and reliance on data from Malaysian university. Hence, future research should include a wider sample, incorporating a broader view from other field of studies or countries. Future research could also explore other areas of blended learning such as the critical success factors and the manners in which can be used to create awareness about blended learning to rural areas. Other than that future research should also look into finding an association between blended learning and the green environment, as blended learning will encourage a paperless learning climate.

\section{Conclusion}

This research study shows the benefits of role-blended learning that helps the teaching environment in universities. This research revolves around students as key participants, hence their views, suggestions and notions are heard and used to gain input on improvements. The study generated results which explains that blended learning is indeed a positive addition to teaching improvement activities and strategies. Embracing Blended Learning by implementing a state-of-the-art learning programs like giving students the best possible opportunity to gain the skills to succeed in the 21 st century. It helps the instructor to identify learning goals and provide the right custom blend of professional development services to the students such as personalizes learning, increase engagement, improves teacher capacity, empowers with data, provides $24 / 7$ access and prepares students for the future. The integration methods of blended learning help students more engaged using a variety of content types. Besides that, it can diversify the educators teaching methods in a good way to approach the problems that arise. Thus, blended learning allows for students to take information home and have their own time to understand it without the pressure of keeping up with the rest of the class. Indeed, as an educator, have an ability to assess student's trends and act accordingly by using e-learning by allowing to update and modify the materials.

In addition, delivering the information to become more effective and efficient with blended learning in place, where through an online platform by providing course materials online means that the students can access the learning content by merely using an electronic device connected to the Internet. Blended learning also makes learning, flexible, where e-learning could help working tight shifts to easily upgrade their skills and knowledge in a convenient manner by accessing online courses, as well as gain new ideas and information through electronic media from the home, office, or any other convenient location

\section{References}

Adas, D., \& Bakir, A. (2013). Writing difficulties and new solutions: Blended learning as an approach to improve writing abilities. International Journal of Humanities and Social Science, 3(9), 254-266.

Agboola, A. K. (2006). Assessing the awareness and perceptions of academic staff in using e-learning tools for instructional delivery in a post-secondary institution: A case study. The Innovation Journal: The Public Sector Innovation Journal, 11(3), 2-12.

Akkoyunlu, B., \& Yilmaz-Soylu, M. (2008). Development of a scale on learners' views on blended learning and its implementation process. The Internet and Higher Education, 11(1), 26-32. http: //dx.doi.org/10.1016/j.iheduc.2007.12.006

Arbaugh, J. B. (2010). Sage, guide, both, or even more? an examination of instructor activity in online MBA courses. Computers \& Education, 55(3), 1234e1244.

Azizan, F. Z. (2010). Blended learning in higher education institution in Malaysia. In Proceedings of Regional Conference on Knowledge Integration in ICT (pp. 454-466).

Bath, D., \& Bourke, J. (2010). Getting started with blended learning. GIHE.

Bach, E.; Forés, A. (2007). E-mociones: Comunicar y educar a través de la red. Barcelona: CEAC.

Benta, D., Bologa, G., Dzitac, I. (2014). E-learning Platforms in Higher Education. 2nd International Conference on Information Technology and Quantitative Management, ITQM 2014. Procedia Computer Science 31, 1170-1176.

Croft, N., Dalton, A., \& Grant, M. (2010). Overcoming isolation in distance learning: Building a learning community through time and space. Journal for Education in the Built Environment, 5(1), 27-64.

Damodharan, V. S., \& Rengarajan, V. (2007). Innovative methods of teaching. In Learning Technologies and Mathematics Middle East Conference, Sultan Qaboos University, Muscat, Oman.

Dorin Herlo, (2015). Improving efficiency of learning in education Master programs by blended learning, Social and Behavioral Sciences, 191 (2015), pp. 1304-1309. http: //dx.doi.org/10.1016/j.sbspro.2015.04.326 
Douglas, K., Lang, J., \& Colasante, M. (2014). The challenges of blended learning using a media annotation tool. Journal of University Teaching and Learning Practice, 11(2), 1-19.

Duţă, N., \& Martínez-Rivera, O. (2015). Between theory and practice: the importance of ICT in higher education as a tool for collaborative learning. Procedia-Social and Behavioral Sciences, 180, 14661473.

Fleck, J. (2012). Blended learning and learning communities: opportunities and challenges. Journal of Management Development, 31(4), 398-411.

Glogowska, M., Young, P., Lockyer, L., \& Moule, P. (2011). How 'blended' is blended learning?: students' perceptions of issues around the integration of online and face-to-face learning in a continuing professional development (CDP) health care context. Nurse Education Today, 31(8), 887-891. http: //dx.doi.org/10.1016/j.nedt.2011.02.003

Hassana, R. A., \& Woodcock, A. Blended learning: Issues and Concerns.

Haro, J. J. de (2009). Las redes sociales aplicadas a la práctica docente. Didáctica, Innovación y Multimedia. Available at http://dialnet.unirioja.es/servlet/articulo?codigo $=2934817$

Hung, M. L., \& Chou, C. (2015). Students' perceptions of instructors' roles in blended and online learning environments: A comparative study. Computers \& Education, 81, 315-325.

Kaur, M. (2013). Blended learning-its challenges and future. Procedia-Social and Behavioral Sciences, 93, 612-617.

Ke, F. (2010). Examining online teaching, cognitive, and social presence for adult students. Computers \& Education, 55(2), 808e820.

Kenney, J., \& Newcombe, E. (2011). Adopting a blended learning approach: Challenges encountered and lessons learned in an action research study. Journal of Asynchronous Learning Networks, 15(1), 45 57

Kinshuk, D., \& Yang, A. (2003).Web-based asynchronous synchronous environment for online learning. United States Distance Education Association Journal, 17, 5-17. Retreived from www.eric.ed.gov/ERICWebPortal/

Kitzinger, J. (1995). Qualitative research. Introducing focus groups. BMJ: British medical journal, 311(7000), 299.

Krasnova, T. (2015). A paradigm shift: Blended learning integration in Russian higher education. ProcediaSocial and Behavioral Sciences, 166, 399-403

Lai, K. W. (2011). Digital technology and the culture of teaching and learning in higher education. Australasian Journal of Educational Technology, 27(8).

Lancaster, J.W., McQueeney, M.L., \& Van Amburgh, J.A (2011). Online lecture delivery paired with in class problem-based learning...Does it enhance student learning? Currents in Pharmacy Teaching \& Learning, 3(1), 23-29. http://dx.doi.org/10.1016/j.cptl.2010.10.008

Marsh, D. (2012). Blended learning creating learning opportunities for language learners. New York: Cambridge University Press.

Monteiro, A., Leite, C., \& Lima, L. (2013). Quality of Blended Learning within the Scope of Bologna Process. TOJET: The Turkish Online Journal of Educational Technology, 12 (1), 108-118.

Moskal, P., Dziuban, C., \& Hartman, J. (2013). Blended learning: A dangerous idea?. The Internet and Higher Education, 18, 15-23.

Moreno-Ger, P., Torrente, J., Bustamante, J., Fernández-Galaz, C., Fernández-Manjón, B., \& Comas-Rengifo, M. D. (2010). Application of a low-cost web-based simulation to improve students' practical skills in medical education. International Journal of Medical Informatics, 79(6), 459-467.

Naidu, P., \& Derani, N. E. S. (2016). A Comparative Study on Quality of Education Received by Students of Private Universities versus Public Universities. Procedia Economics and Finance, 35, 659-666.

Patton, M. Q. (1990). Qualitative evaluation and research methods . SAGE Publications, inc.

Poelmans, S., \& Wessa, P. (2015). A constructivist approach in a blended e-learning environment for statistics. Interactive Learning Environments, 23(3), 385-401.

Railean, E. A. (2017). Impacts of Digital Revolution on Learning. In User Interface Design of Digital Textbooks (pp. 1-22). Springer, Singapore.

Roby, T., Ashe, S., Singh, N., \& Clark, C. (2013). Shaping the online experience: how administrators can influence student and instructor perceptions through policy and practice. Internet and Higher Education, 17, 29e37.

Schoonenboom, J. (2012). The use of technology as one of the possible means of performing instructor tasks: putting technology acceptance in context. Computers \& Education, 59(4), 1309e1316.

Singh, H., \& Reed, C. (2001). A white paper: Achieving success with blended learning. Centra software, 1.

Smythe, M. (2011). Blended learning: A transformative process. Retrieved on December, 12, 2011. 
Smyth, S., Houghton, C., Cooney, A., \& Casey, D. (2012). Students' experiences of blended learning across a range of postgraduate programmes. Nurse Education Today, 32(4), 464-468. http://dx.doi.org/j.nedt.2011.05.014S.

Wai, C. C., \& Seng, E. L. K. (2014). Exploring the effectiveness and efficiency of blended learning tools in a school of business. Procedia-Social and Behavioral Sciences, 123, 470-476.

Wu, J.-H., Tennyson, R. D., \& Hsia, T.-L. (2010). A study of student satisfaction in a blended e-learning system environment. Computers \& Education, 55(1), 155-164. doi:10.1016/j.compedu.2009.12.012

Wu, J.-H., Tennyson, R. D., Hsia, T. L., \& Liao, Y. W. (2008). Analysis of e-learning innovation and core capability using a hypercube model. Computers in Human Behavior, 24, 1851-1866. doi:10.1016/j.chb.2008.02.008 